\title{
Design e o crochetar no universo feminino
}

\author{
Ana Célia Carneiro Oliveira; \\ Nadja Maria Mourão; \\ Flávia Neves de Oliveira Castro
}

resumo:

O crochetar é um mergulho de introspecção e de realização do saber-fazer relatado por empoderadas mulheres que, ao segurar nas mãos agulhas e linhas se distanciam das questões cotidianas. Esta afirmativa advém de uma pesquisa com artesãs e artistas por seus saberes e fazeres em produção artesanal com crochê em comunidades tradicionais e ambientes urbanos. Buscou-se entender o porquê da afirmativa que crochetar, além de trabalho, serve como atividades terapêuticas para algumas mulheres. A pesquisa buscou também observar a presença do crochê no mundo contemporâneo, principalmente no momento atual de isolamento social no território brasileiro. Pelo método qualitativo, este trabalho se fundamenta nas relações artesanais com o design e suas contribuições sociais. Em resultados, apresenta-se um panorama diversificado de experiências femininas e estimulo a pratica do crochê como recurso em qualidade de vida e novas possibilidades perante a realidade que se descortina no novo mundo.

palavras-chave:

Design; crochê; gênero feminino; qualidade de vida; felicidade 


\section{Introdução}

Os reflexos causados pelo isolamento social devido à pandemia do coronavirus conduzem a observação das pesquisas de realidades (e em andamento) sob novos olhares. O designer, por suas habilidades de investigador e analista, debruça sobre o prisma dos efeitos estabelecidos na sociedade, comparando-os com dados antecessores. Atividades caseiras e o fazer manual estendem-se em arranjos de equilíbrio mental ou passa-tempo para a sociedade confinada em seus lares.

O crochetar é um mergulho de introspecção e de realização do saber-fazer relatado por empoderadas mulheres que, ao segurar nas mãos agulhas e linhas se distanciam das questões cotidianas. Esta afirmativa advém de uma pesquisa com artesãs e artistas por seus saberes e fazeres em produção artesanal com crochê em comunidades tradicionais e ambientes urbanos.

$\mathrm{Na}$ atualidade, fazer crochê tornou-se um hobby saudável, capaz proporcionar equilíbrio e tranqüilidade. Observa-se que médicos e psicólogos já recomendam atividades artesanais, como o crochê, no tratamento de doenças como o Alzheimer e Parkinson. O crochetar estimula a capacidade de concentração, proporcionando alívio da ansiedade e diminuindo a angústia. Contudo, como toda atividade repetitiva é necessário cuidado com a postura do corpo, com as mãos e também com a visão.

Para a atividade de fazer crochê deve-se seguir a receita ou o passo-a-passo que conduz ao produto completo. Ou seja, antes de tudo, é preciso executar uma lista de materiais necessários, quais as proporções e técnicas utilizadas. Muitas peças são pré-estabelecidas por terem sido experimentadas anteriormente. Contudo, para artistas, criativos e inovadores é preciso experimentar novos modelos, sabendo-se que se pode desmanchar todo o trabalho executado e recomeçar.

$\mathrm{Na}$ atualidade, o design se apropria do fazer manual para obter resultados diferenciados e exclusivos. O crochê oferece recursos como materiais - fibras vegetais e sintéticas de variadas cores, por exemplo, e formas inovadoras que podem ser aplicados na moda e nos ambientes internos e externos, tanto em produtos de grifes, manifestações artísticas, quanto em projetos sociais.

A estilista Raquell Guimarães levou o tricô e crochê para a sofisticação de peças de grife, comercializadas em Paris, Tóquio e Nova York. Contudo, as peças não são confeccionadas por mulheres, mas por condenados da Casa de Detenção São Paulo. Trata-se de um projeto social que emprega os presidiários, oportunizando além do trabalho uma atividade que auxilia na memória e concentração. A estilista relata a gratificação em saber que os trabalhos, além da exclusividade, carregam as dores e as alegrias destas pessoas, conforme Dias (2014).

Para alegria de muitos, foi criado o dia do crochê em 19 de setembro, em eventos como o Crochêtalks, em São Paulo. Nesta data muitos artesãs e artesãos apaixonados com o crochê se reúnem para trocar conhecimentos, conversarem sobre seus trabalhos, conquistas e dificuldades, conforme site circulo.com.br. Nos encontros entre os apaixonados com o crochê obteve-se declarações de satisfação por essa atividade que, muitas vezes, foi utilizada para tratar de angustia e solidão.

Durante o isolamento social, em lives de encontros sociais com pessoas que fazem crochê, obtiveram-se declarações de lazer, alívio e satisfação por utilizarem este recurso como estabilizador emocional. O lazer "é um conjunto de atividades que podem proporcionar repouso, divertimento, formação desinteressada após o indivíduo livrar-se das obrigações profissionais e familiares" (DUMAZEDIER, 1973, p.34).

Percebe-se que o fazer manual, como atividade tradicional, permanece como vivência e como economia social importante para o desenvolvimento local. O saber-fazer, passado de geração a geração, conserva a memória cultural, trata-se da preservação dos valores herdados de gerações antecessoras, conforme Mourão e Oliveira (2020).

Buscou-se entender o porquê da afirmativa que crochetar, além de trabalho, serve como atividades terapêuticas para algumas mulheres. A pesquisa buscou também observar a presença do crochê no mundo contemporâneo, principalmente no momento atual de isolamento social no território brasileiro.

Pelo método qualitativo, este trabalho se fundamenta nas relações artesanais com o design e suas contribuições sociais. A fundamentação do referencial teórico de apresenta como passo inicial da pesquisa. Com foco na temática e como o tema é extenso, realizou-se um recorte em breve histórico do crochê, principalmente sob a visão feminina, e suas manifestações em algumas comunidades tradicionais e como veículo de design e arte. 
Sob o olhar do design e suas contribuições sociais, espera-se estimular a expansão do fazer manual em crochê tanto no processo satisfatório do fazer, quanto em produtos com melhor qualidade e durabilidade.

\section{Breve histórico do crochê como atividade feminina}

Segundo Ruthie Marks (1997), a palavra "crochê" tem origem no francês medieval croké, termo que designava um instrumento de ferro recurvado, uma espécie de gancho, que permitia suspender ou segurar alguma coisa. No século XIX, surge na França a expressão broder au crochet (literalmente, "bordar com o gancho"). A agulha de crochê possui, em sua ponta, um gancho que provoca que a linha seja puxada e consente a criação do ponto.

O trabalho manual tem seus primeiros registros de 12.000 anos. Na Era Neolítica, os primeiros homens usavam o princípio da tecelagem entrelaçando pequenos galhos e ramos para construir barreiras, escudos e cestas. Os pássaros construindo seus ninhos e as aranhas suas teias serviram como fonte de inspiração para o homem que, a partir da observação, criou uma técnica semelhante para construir objetos necessários à sua sobrevivência. Com o progresso das técnicas de cultivo e com a apropriação dos trabalhos manuais os homens primitivos descobriram que as fibras vegetais como o linho poderiam ser utilizadas para união de peças, facilitando a construção das roupas que eram feitas com peles de animais e, assim, a tecelagem caracterizou-se como uma atividade importante para a vida social deste período (FONSECA, 2015, p. 45).

Segundo os historiadores, os afazeres em crochê têm ascendência na Pré-história. A arte do crochê, como se aprecia presentemente, foi desenvolvida no século XVI. O escritor dinamarquês Lis Paludan (1995) arriscou encontrar a origem do crochê na Europa e baseou determinadas hipóteses. Uma dessas hipóteses é de o crochê se ocasionou na Arábia e chegou à Espanha pelos caminhos comerciais do Mediterrâneo. Também possui sinais posteriores do artifício em tribos da América do Sul, que utilizavam ornatos de crochê em cerimoniais da juventude. Na China, bonecas eram feitas com o mesmo artifício, não obstante o autor assegura que não há proeminência palpável sobre quanto ancestral é a arte do crochê.

Portanto, a observação de Paludan (1995), indica que o crochê possivelmente tenha sido adiantado mais espontaneamente do bordado chinês, uma forma muito antiga de bordado experimentado na Turquia, Índia, Pérsia e norte da África, que chegou a Europa.

Veras (2007) relata que não se sabe ao certo a origem do crochê, no entanto, este estilo de artesanato amimava muito a Rainha Vitória em 1700, após ser difundido no Oriente médio por ser usado como repetição da renda. Em breve tempo, o crochê conquistou a realeza por se apresentar mais sofisticado em texturas e diferente tipos de emaranhados. Segundo a autora, artefatos executados com linhas são de acordo com a tradição concretizados por mulheres. Legado histórico que data da conquista Portuguesa, assim a técnica do crochê arranja da história humana e do seu viver diário, constituindo-se na moda, na decoração ou até mesmo como afazer básico de valor financeiro essencial para muitas mulheres que habituam no interior ou na capital.

As mulheres sempre tiveram funções mantenedoras de tradições, tanto em famílias abastadas, quando e as mais pobres. Contudo, por mudanças das atividades em sociedades urbanas no século $\mathrm{XX}$, as atividades artesanais tornaram-se mais escassas.

No século XX, as mulheres passaram de dona de casa ao papel de esteio da família, com a industrialização, saíram de dentro de seus lares para trabalhar fora, muitas delas tinham agora o papel de chefes de família, desta maneira, houve um afastamento das meninas em relação às tradições do lar, e a pratica de fiar, bordar, coser, crochetar, se distanciava cada vez mais, ao ponto de perder-se a tradição que antes caracterizava o contexto familiar e cultural do grupo (ANDRADE, 2017, p.64). 
Barbosa (2014), ao consultar o Instituto Brasileiro de Geografia e Estatística (IBGE), verificou que o mesmo aponta o gênero feminino no artesanato. Do registro de 8,5 milhões de artesãos, constatou-se que $87 \%$ são mulheres. Os dados do IBGE reforçam que na história do trabalho da mulher no Brasil, os afazeres manuais ligados a criação de comidas, tecelagem, pães e cuidados com o lar sempre foram atribuições da figura feminina.

Segundo Lemes; Pereira (2020), a difusão acontece através das mulheres, sejam elas da mesma família ou amigas, vizinhas, enfim, independentemente das raízes culturais, como um ato do fazer manual coletivo. É a presença da mulher que constrói histórias e transmite a ciência para as meninas, principiando desde a infância - aproximadamente entre os 6 aos 11 anos de idade.

O saber-fazer do ofício do tecer liga-se à tradição, desde tempos remotos, associandose à figura feminina e ao desenvolvido no âmbito doméstico. No processo de transmissão, este saber ultrapassa a materialidade das peças produzidas, sendo associado ao fator de afeto entre mestre e aprendiz e ainda ao valor de estima dado aos produtos, que trazem consigo a memória, a identidade e a tradição das mulheres artesãs. (LEMES; PEREIRA, 2020, p. 180).

Nos dias atuais, para a pluralidade das artesãs, a arte de arranjar crochê ou bordar é vivenciada desde a infância. Assim o aprendizado inicia-se cedo, segundo Engels (1985), como exemplo em comunidades onde a brincadeira rapidamente se transforma em ofício, indo embora o ócio infantil e iniciando o formato futuro de suas vidas. Este estilo de vida faz parte de uma estratificação da vida em sociedade de uma comunidade e seus comportamentos em relação ao meio ambiente e aos outros seres humanos. $\mathrm{O}$ autor também reflete que a maneira que o ser humano cria seus ofícios que o mantem financeiramente é uma forma marcante de anunciarem suas vidas, um acentuado modo de vida deles, assim são eles.

Ainda segundo Almeida (2004), o termo "modo de vida", reflete o pensamento que envolve o conceito de cultura com seus estudos da vida diária e popular de comunidades tradicionais, envolvida na sua diversidade de portas simbólicas.

\section{Crochetando em comunidades tradicionais}

Denomina-se saberes e fazeres os conhecimentos e os métodos de aplicação destes, transmitidos por gerações aos membros de uma comunidade. As parteiras, por exemplo, aprenderam a executar os partos na prática, a necessidade as obrigou aprenderem as técnicas, que são passadas de uma geração à outra, praticadas por mulheres que se adéquam ou que se instituem parteiras. Por muitos séculos, foram as parteiras as responsáveis por muitas vidas em suas regiões ou em outras, as quais elas eram chamadas. Não havia um salário para a parteira, quando muito, alguma ajuda por gratidão. Ela se sentia útil em estar ajudando um ser humano a nascer, utilizando as técnicas e sua crença e seus remédios caseiros. A qualquer momento, a parteira estava pronta para ir atender ao parto, levando seus saberes aos fazeres, conforme Santos (2015).

Cuidar da vida exige reconhecer e adquirir a consciência do pertencimento. "Se acrescentamos à natureza primitiva, a cultura, sabemos que sem a natureza primitiva, pura não há cultura" (BOGO, 2008. p. 30). Essa relação do ser humano com a natureza, dada pela convivência diária com os elementos físicos, conduz a um estado de confiança ao conhecimento adquirido pelas práticas.

Entre as técnicas utilizadas para o artesanato, destaca-se a utilização do "linho" da seda do buriti para confecção de objetos em crochê. $\mathrm{O}$ crochê se revela nas mãos hábeis das artesãs, donas de casa, que dividem com parceiros e parceiras a coleta desta matéria-prima. A retirada do linho de buriti é um ato que demanda muita experiência. A mão não pode tremer para não estragar a fibra, ou seja, para não quebrar a estrutura do feixe de fibras, que irá se transformar em uma "linha"

Pode haver alguma relação do crochê com a cultura européia, desde os tempos de colonização. Mas, não há comprovações, pois as artesãs, quando consultadas, não sabem ao certo quem começou a utilizar está técnica com a fibra do buriti. 


\subsection{Grupo de artesãs de Barreirinhas - Maranhão}

Na cidade de Barreirinhas, há vários grupos que trabalham com a fibra de buriti, alguns fortalecidos por projetos e cursos que qualificaram o trabalho das artesãs. No entanto, para o desenvolvimento são necessários que, mais pessoas participem do artesanato fortalecendo o pólo comercial de artesanato. As artesãs de Barreirinha após anos e anos de aperfeiçoamento das técnicas, conseguem ser multiplicadoras, ensinando a outras mulheres que desejarem trabalhar com a fibra do buriti.

Com o linho do buriti são produzidos diversos produtos de artesanato, com modelos bastante diversificados: bolsas, carteiras, chapéus, cintos, roupas, redes, forros de mesa, tapetes, entre outros. As técnicas se diversificam sendo o crochê a mais popular entre elas.

Para fazer o crochê ou o tear é preciso preparar o material em etapas que utilizam de técnicas e práticas. Assim, a fibra fresca, após o cozimento, passa pelo processo de tintura com ervas da região, ficando uma perfeita coloração: cascas naturais de açaí (Euterpe oleracea) dão o tom roxo-escuro; pariri (Arrabidaea Chica Verlot.), o salsão (Ipomoea sp), a cor verde; do urucum (Bixa orellana L.), o laranja; e do açafrão (Curcuma longa), o amarelo. As artesãs usam mordenete como o sabão e as cinzas de madeira. Alguns corantes como urucum cuja cor fixa melhor, empregando como mordenete o sabão em barra, deve ser lavado até retirar o excesso da cor, para que o produto não manche outros materiais (MOURÃO, 2020).

$\mathrm{O}$ encontro com as artesãs ocorreu na loja da cooperativa em Barreirinhas. Neste mesmo espaço elas se encontram para produzir (tecer o crochê com o linho de buriti), atenderem os clientes e para descansar dos problemas de casa. Dona Maria, uma das artesãs, disse-nos que ela vai para a loja tecer com as amigas porque para ela é o momento de terapia: - "A gente vem prá cá todas as tardes, ou assim que termina tudo em casa, para trocar ideias e aprender também. Na conversa a gente aprende muito". Depois de fazer sua declaração, seus olhos estavam brilhando de emoção.

Dona Rosa revelou que já viu muita gente entrar e sair da cooperativa, é difícil ter que dividir coletivamente. Também revelou que mora longe da cidade, mas ela vai mesmo assim. "Trabalhar juntas faz bem para todos nós", completa Dona Rosa.

A seguir na figura 1, alguns produtos desenvolvidos com a fibra do buriti, pelas associadas de organizações de artesãs (cooperativas e associações) na cidade de Barreirinhas, no Maranhão.

Figura 1 - Produtos de crochê com linho de buriti em Barreirinhas/MA.

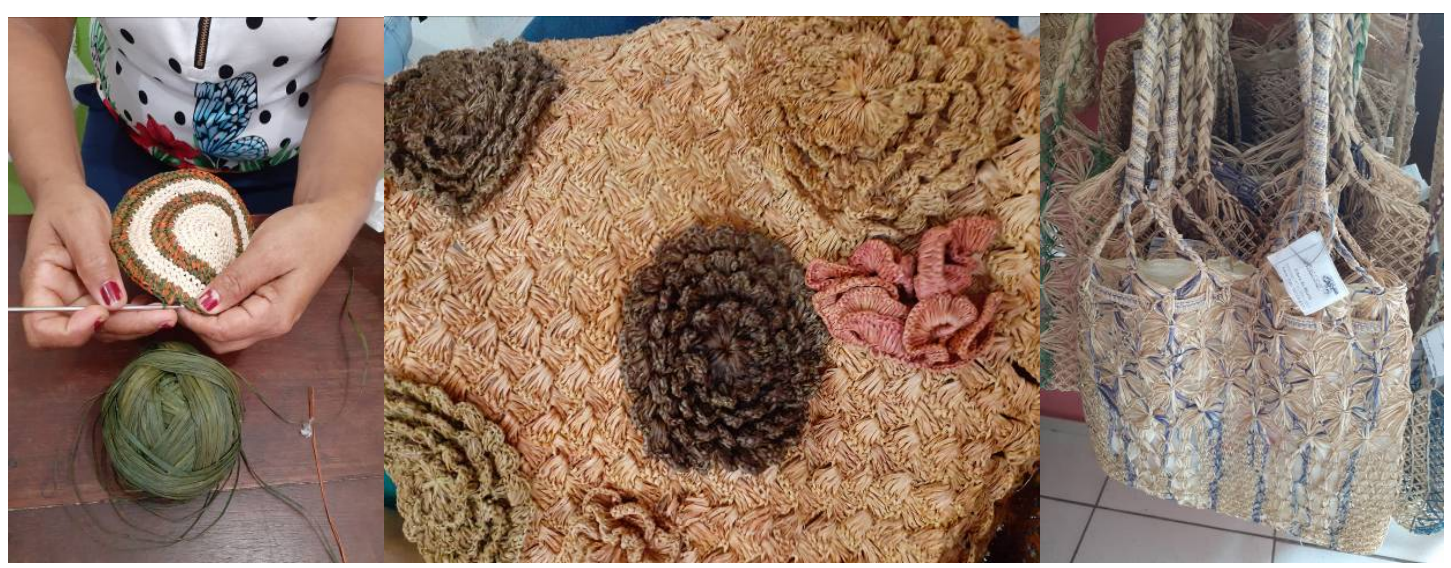

Fonte: Acervo da Pesquisa, 2020.

As mãos habilidosas são fiscalizadas pelo olhar atento, onde cada ponto tem uma função do tear. As formas seguem o projeto pré-estabelecido do produto que se espera obter. Contudo, se algum ponto não se apresenta com a mesma firmeza dos demais, todo o processo é desfeito até o conjunto dos pontos possam apresentar a harmonia na trama. 


\subsection{Grupo de artesãs da Comunidade de Piranhas/Água Doce - Maranhão}

O artesanato em crochê é sem dúvida uma atividade tradicional, como uma forma de passar o tempo e aclamar a alma. Muitas artesãs declaram que é uma terapia e que as mãos se acostumam com os pontos em uma sequencia de pontos que nem se percebe o tempo passar.

O crochê não possui uma origem definida, mas há sinais que tenha surgido na China como um tipo de costura e que se popularizou pelo Oriente Médio até chegar à Europa por volta de 1700. O nome crochê tem origem na palavra francesa croc, que significa gancho. No final da Idade Média foi usado como uma reprodução de renda, um produto apreciado pela rainha Vitória que conquistou o gosto dos europeus, ganhando sofisticadas texturas e trançados, misturados a bordados e a apliques com pedrarias (KELLY, 2007).

Em relação ao artesanato crochê, é possível ponderar a análise de Cerqueira (2012), sobre os feitios do material, que leva à efetivação da memória coletiva por meio de artefatos tangíveis, aplicando-se a peça confeccionada artesanalmente; e os aspectos imateriais, que permitem a interpretação das relações entre as amostras simbólicas e a desenvolvimento das identidades culturais, harmônica com a técnica de artesanato em si.

Na comunidade de Piranhas de Água Doce no Maranhão, as mulheres não sabem explicar quando começaram a fazer o crochê, mas é uma atividade que aprenderam com as avós, tias e vizinhas. O grupo de artesãs é consolidado e numeroso, mas elas produzem em casa, entre uma tarefa e outra, com as crianças ao entorno aprendendo também.

A comunidade possui uma beleza natural com buritizais e outras palmeiras, há também muitas árvores frutífera. Mas, o material da natureza não as interessa tanto, preferem fazer seus produtos com linhas e lãs compradas na capital.

Figura 2 - Produtos de crochê na comunidade Piranhas de Água Doce/Maranhão.

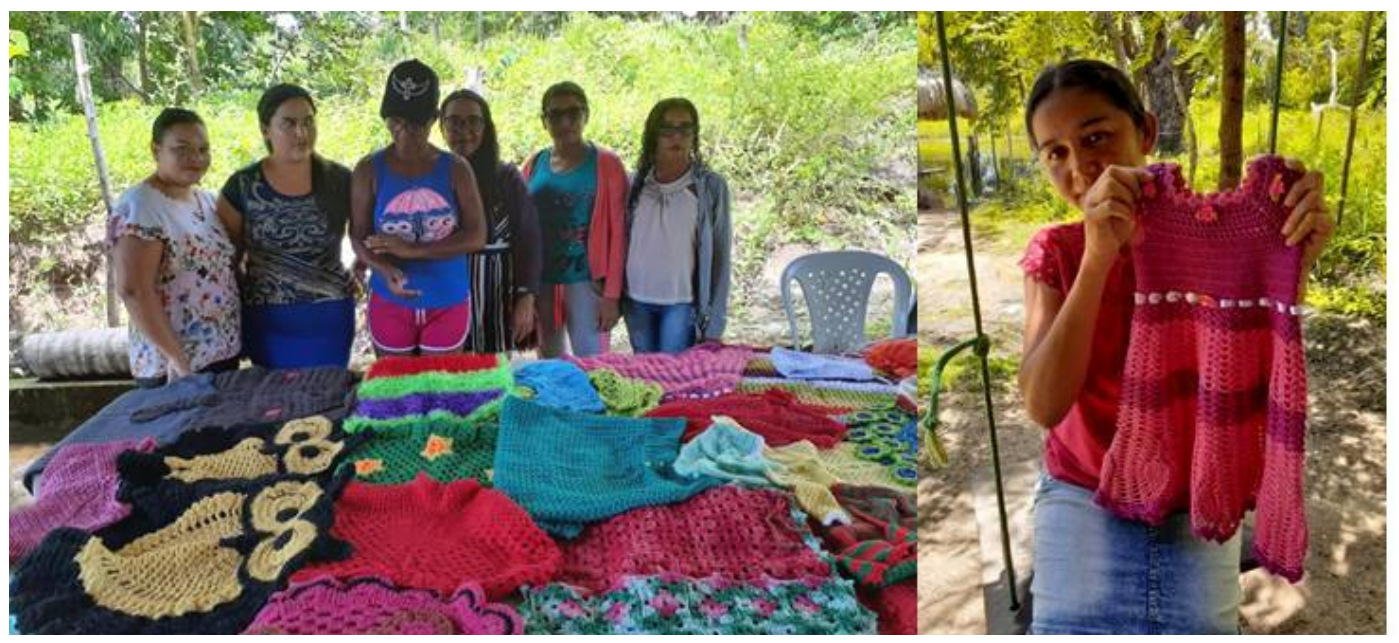

Fonte: Acervo da Pesquisa, 2020.

Sob as análises do Termo de Referência do Artesanato - MDIC N²9/2010, a produção artesanal deste grupo se estabelece na qualificação de "Artesanato Tradicional", uma vez que, as técnicas do trabalho em linha no crochê foram absorvidas por gerações antecessoras e ainda permanecem. As artesãs preferem utilizar linhas industriais. Elas dizem que as linhas sintéticas não desbotam e quando a peça é bem confeccionada, o produto terá uma extensa durabilidade. Vestidinhos infantis, tapetes e objetos decorativos podem durar gerações, caso sejam cuidadosamente utilizados.

\section{0 crochê como manifestação artística e do design}

A arte tem o conceito em constante evolução, sua origem no latim nas formas ars, artis, a partir de una raiz grega em téchne. Em seu sentido etimológico, trata-se de uma habilidade adquirida, da qual se 
opõe às faculdades concedidas pela natureza. A palavra ofício deriva do latim officium e significa realizar um trabalho aplicando técnicas e habilidades específicas. No regime de trabalho denominado artesanato, os ofícios estão ligados às habilidades artesanais e à figura do artífice ou artesão. De certa forma, "a história do artesanato se confunde com a história do homem, pois a necessidade de produzir bens de uso rotineiro e ornamentos é expressão da capacidade criativa e do trabalho" (FACHONE, 2012, p. 61).

A base do trabalho do artista e do designer é o olhar, o olhar nos dois âmbitos tem peça fundamental e se expande para a observação, investigação, a pesquisa constante na criação. A experiência vira prática, e a história uma narrativa, um conceito. A arte é um conjunto de atos pelos quais se muda a forma, se transforma a matéria oferecida pela natureza e pela cultura. $\mathrm{O}$ que transforma a matéria em "arte" é a quantidade de poética que se coloca nela. (Bosi, 1986). Ela é uma forma de devolução do que faz parte do universo onírico e é acrescentado nele algo que ainda não se tenha pensado, o que não está no Google. O que ainda não existe e é único, mas ao mesmo tempo, tem um grande potencial multiplicador e reflexivo.

Muitas mulheres estão adaptadas ao reaproveitamento de coisas, roupas e alimentos, hábito aprendido e replicado na família, com as mães, tias, avós. O que nos leva a outro pilar do Design: a sustentabilidade. A interseção entre Arte e Design mostra-se muito produtiva. Torna-se evidente a importância do Design e da Arte em todas as áreas de conhecimento, sugerindo produtos e métodos inovadores que atendam as prerrogativas de cunho social, ressignificando práticas e possibilitando novos caminhos.

\subsection{Arte e Design no crochê}

A artista visual e designer de São Paulo, Karen Bazzeo que criou o atelier Dolorez Crochez. Nascida em Bauru, Karen diz que aprendeu a fazer crochê com sua mãe e que encontrou suas peças, em um antigo baú. Resolveu então usar o crochê como sua forma de expressão. Esta atitude é também uma valorização da memória.

Nossas memórias estão diretamente ligadas à afetividade e constroem um universo de lembranças que são reativadas todos os dias por coisas que vemos, sentimos, por determinados assuntos, cheiros, lugares e pessoas, nessa mesma direção que buscamos apresentar estímulos que pudessem trazer memórias à tona (PEDRO, ALVES, 2019, p.342).

"Percebi que minhas mãos teciam tramas de fios e sentimentos. São elas que falam por mim, que colocam pra fora, que trazem o subjetivo ao objetivo". Karen diz que vem se dedicando ao chamado "craftivismo". Como já dito anteriormente, este termo é usado para designar uma forma de ativismo que se vale de técnicas artesanais para transmitir mensagens anticapitalistas, ambientalistas e feministas. "Como o meu trabalho é muito do que eu sinto, do que eu quero expressar, é natural que minhas opiniões políticas se reflitam nele. É uma maneira de "milita", depoimento para a Folha de São Paulo (2016). Na figura 3, são apresentadas algumas imagens das intervenções de Karen em espaços públicos de São Paulo. 
Figura 3 - Crochê urbano de Karen Bazzeo.

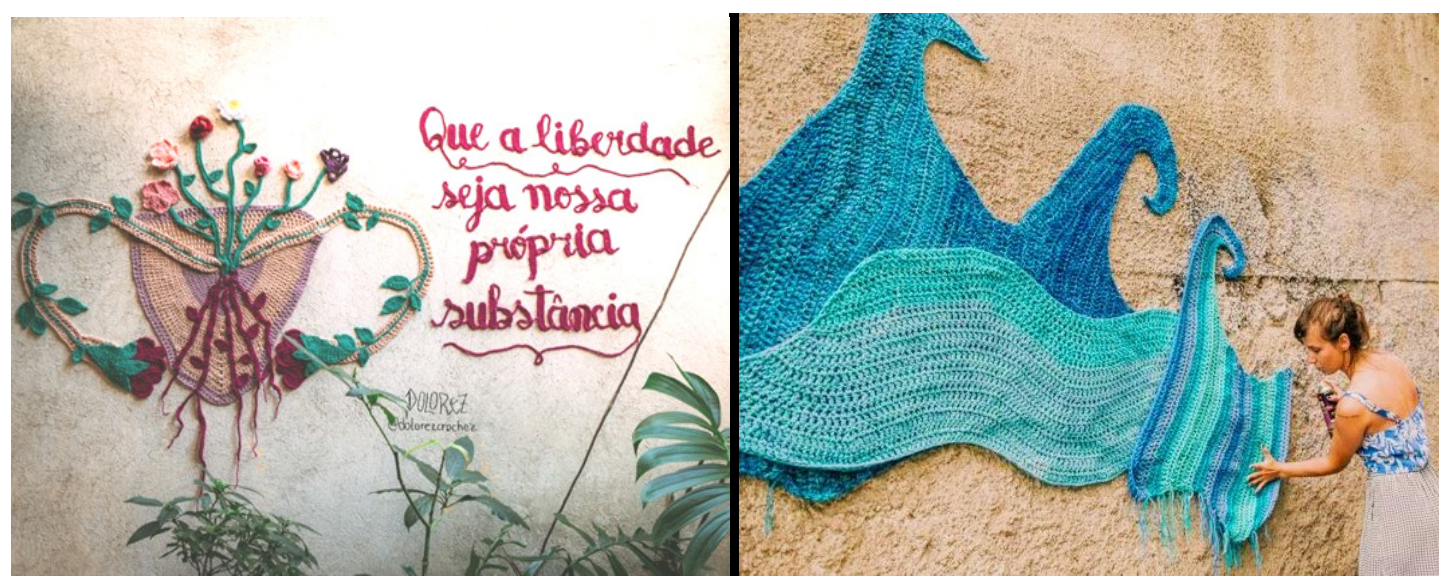

Fonte: $<$ https://www.bbc.com/portuguese/noticias/2016/02/160218_galeria_croche_graffiti_pai $>$. Acesso em: 18 de mai. de 2020.

Para ela, a ocupação de áreas públicas com intervenções artísticas é capaz de transformar lugares que antes não eram tão notados em uma oportunidade para as pessoas se relacionarem melhor com seu cotidiano. "Fico muito feliz quando consigo passar uma mensagem através da arte e quando tenho uma resposta das pessoas na compreensão e especialmente na identificação com o meu trabalho. Perceber que de alguma forma as pessoas se identificaram, se inspiraram e vão conseguir sair do lugar que estão é muito gratificante", relata Karen, conforme D'Ornelas (2019).

\subsection{Crochê em intervenção urbana}

Outro estudo do crochê como manifestação artística e do design é o projeto realizado como intervenção na cidade de Belo Horizonte em Minas Gerais, através do ensino do crochê com a participação da comunidade, em praças e lugares de convivência pública. Essas intervenções ocorrem quinzenalmente, e reúnem grupos de pessoas interessadas em aprender o crochê e contribuir para "vestir" algum pedacinho da capital mineira, seguindo o movimento Yarn Bombing. "Além de vestirem o mobiliário urbano com tramas coloridas e proporcionar uma nova experiência estética e sensorial na cidade", as pessoas integrantes do coletivo também promovem oficinas para a confecção das peças usadas nas ações. A atividade propõe um novo olhar sobre a cidade, de forma que possamos interagir com os espaços e ressignificar os pontos urbanos (MELO, 2016, p.13).

$\mathrm{Na}$ figura 4, observam-se as atividades com a comunidade no projeto Vestíveis Urbanos, na Praça da Liberdade, uma das mais importantes da metrópole.

Figura 4 - Projeto de intervenção urbana - Vestíveis Urbanos.

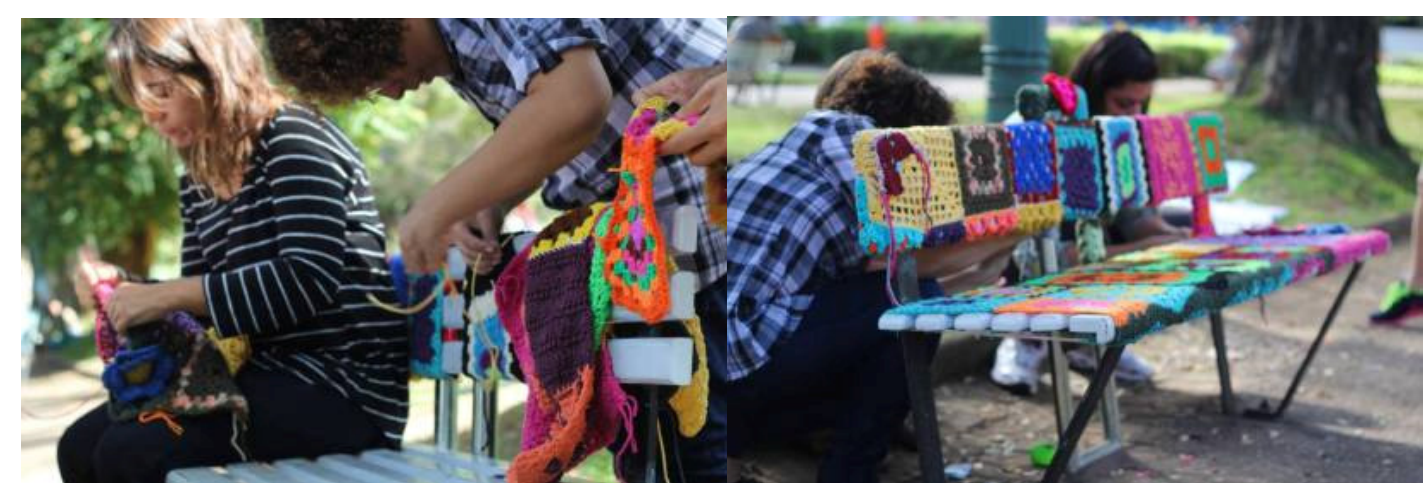

Fonte: $<$ https://vestiveisurbanos.wordpress.com/>. Acesso em: 18 mai. 2020. 
Graças às mãos habilidosas dos participantes, a arte do crochê e do tricô se reinventa e encanta as novas gerações. Esta, como outras intervenções similares, visam retomar, alterar ou acrescentar novos usos, funções e propriedades em um espaço, incentivando a ocupação da população neste espaço, tornando-o um lugar de vivências. Valores reforçados pelo autor (GEHL, 2013, p. 147) que diz "uma boa cidade é como uma boa festa, os convidados ficam porque estão se divertindo". Trabalhos de intervenção podem acontecer em espaços externos, geralmente públicos de grande circulação humana.

Trata-se também de uma atividade da memória cultural, transmitida entre as gerações e que neste modelo de projeto se reinventa. Além de ser um resgate da interação com a cidade, onde as relações interpessoais são incentivadas. O fazer manual e a técnica artesanal são apresentados àqueles que estão dispostos a conhecê-la e assim, cada participante se torna peça ativa na construção de uma cidade mais colorida e agradável aos olhos. Dessa maneira, os habitantes da cidade passam a ser agentes ativos do organismo urbano, onde todos fazem parte e estão contribuindo para o bem-estar e a melhoria da sociedade, atuando em conjunto.

O sentido estético está na atualidade presente em grande parte da vida cotidiana das pessoas. Transformar um ofício em arte é construí-lo com afeto e com qualificação de especial; prazer pessoal e que finde com interesses estéticos de outras pessoas. Escolher as cores, os fios, as misturas e seus ritmos em intencionalidades ou não, na cadência das laçadas, formando expressões artísticas através do artesanato cultural geracional. Sobre valores estéticos destaca-se que, "[...] a vivência estética influi sobre o aspecto subjetivo de atribuição de valor a um objeto com maior ou menor elaboração, a partir do referencial do sujeito" (RICHTER, 2003, p. 111).

Joana Vasconcelos revela a beleza na expressão artística utilizando o artesanato como meio de discussão e crítica da função e ocupação da mulher ao longo dos séculos, nas atividades da vida cotidiana. Apresenta inclusive que o artesanato serviu para manter a mulher no espaço privado e como atividade de trabalho ou complementação das despesas do lar. "Em suas obras, desloca o artesanato para o espaço público e ao fazê-lo altera suas funções originais. Discute tanto as questões do feminino quanto do trabalho artesanal, de forma bem humorada, numa profusão de cores que não abandona a noção de belo, mas que a reforça" (VAZ; PANEK, 2017, p.327).

\section{Análises dos saberes e fazeres com crochê no universo feminino}

Nas bases da Linguagem visual "o ponto é a unidade de comunicação mais simples e irredutivelmente mínima" (DONDIS, 2000, p. 53). No crochê, os primeiros pontos, ainda que simples, promovem um grau de importância em todos os trabalhos começados. Assim, a linha descreve uma forma e os pontos do crochê através das linhas vão se compondo em múltiplas ideações que a mente pode conceber.

De acordo com Fonseca (2015; p. 52), a arteterapia é "uma atividade terapêutica que atua na prevenção, recuperação e manutenção da saúde psíquica do indivíduo por mediar, através da utilização de diferentes técnicas artísticas, a comunicação do indivíduo consigo mesmo". Esse é uma porta muito ativa que promove a aparecimento de emoções e de sentimentos que fazem parte do inconsciente.

Assim como outras atividades que envolvem linhas, agulhas e trabalhos manuais, o crochê encontra-se na natureza das ocupações prazerosas e afetivas, corroborando no tratamento de doenças. Isso ocorre porque o cérebro libera dopamina, um neurotransmissor responsável por designar uma sensação de prazer e satisfação. A dopamina está conexa com o chamado "sistema de recompensa", o que explica Santos (2020), que é um rede neuronal no cérebro que entusiasma espontaneamente as emoções dos seres humanos. Avalizando o entusiasmo para executar algumas agilidades, como a percepção de felicidade quando comemos ao ter fome. Assim que os neurônios humanos são acionados, eles aprovam a dopamina no cérebro humano intensificando a percepção de prazer.

Os seres humanos se entristecem ou se alegram de maneira espontânea segundo DePaulo; Hortiz (2000), em implicação de eventos da vida. Essa experiencia, de altos e baixos diários no afeto humano, é universal e natural.

O crochê, além do prazer gerado pela dopamina, é uma excelente atividade do ócio criativo, capaz de promover ações sociais. Dessa forma, "[...] a arte permite ao ser humano a liberação de seus sentimentos e emoções, aumentando a qualidade afetiva das relações interpessoais, pela melhora da comunicação, fortalecimento da autoimagem e redescoberta de potenciais criativos" (GUEDES et al., 2017; p. 731). 
O ser humano está na era e no momento da informação excessiva. Vivem mergulhados em um fluxo de informações instáveis e assim, atitudes e posicionamentos podem se transformar em problemas de depressão e solidão. A arte pode ajudar em todo o processo e ser um instrumento efetivo para desenvolvimento de agilidades criativas e significativas.

A criação de um trabalho garante a autoestima e a autoconfiança. Reforçando o ego, a arteterapia direciona a subjetividade, tornando-se cada vez mais estruturada no percurso de sua autonomia ou autoria de pensamento. Favorecendo a relação com o outro, o indivíduo tem a possibilidade de se sentir incluído ou fazer parte de um grupo, desenvolvendo sentimentos de companheirismo, satisfação, identificação, semelhança, apoio, proteção e ajuda (GUEDES et al., 2017, p. 739).

Dentre as diversidades de peças criadas pelo universo feminino, salienta-se: as peças para decoração da casa (toalhas de mesa, caminhos de mesa, almofadas, cortinas, tapetes, colchas para a cama, enxovais de casamento) e peças de vestuário (roupinhas de bebê, blusas, casacos, cachecóis). Em relação aos modelos de artefatos, Martins $(1973$, p. 16) lembra que "a opção dos temas incide de forma singular a cada artesão e que é entusiasmada pela cultura e pelos modos de vida que vivência culturalmente".

$\mathrm{Na}$ figura 5, são apresentados os modelos de desenhos tradicionais em almofadas, conhecidos como quadrados da vovó, modelos tradicionais dos anos de 1970.

Figura 5 - Crochês com desenhos tradicionais dos anos de 1970, conhecidos por quadrados da vovó.

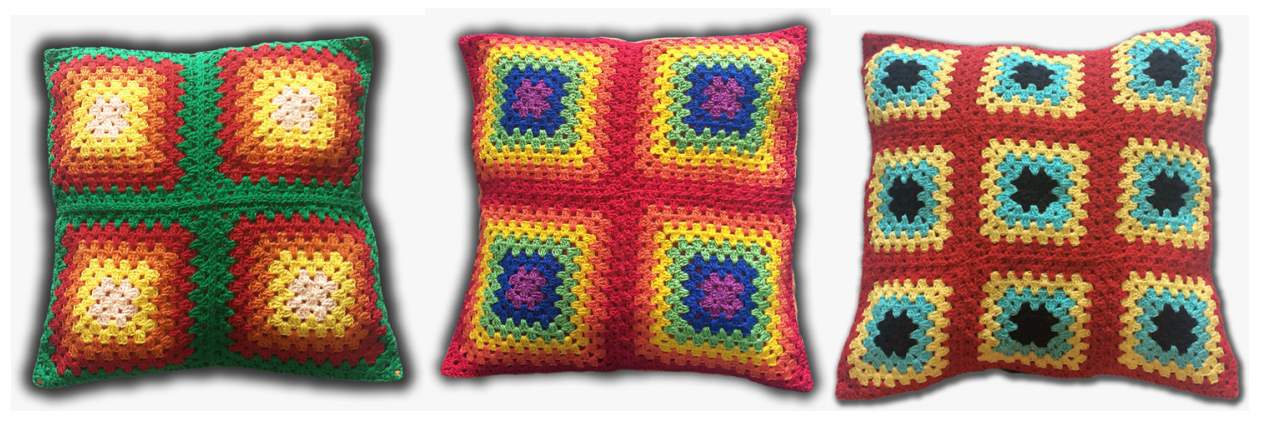

Fonte: Acervo da pesquisa, 2020.

A vida "privada" constitui o testemunho de um tempo coletivo. Ecléa $(2003$, p. 63) lembra a importância das perturbações e dos silêncios. "Os lapsos e incertezas das testemunhas são o selo da autenticidade... A fala emotiva e fragmentada é portadora de significações que nos aproximam da verdade. Aprendemos a amar esse discurso tateante, suas pausas, suas franjas com fios perdidos quase irreparáveis".

$\mathrm{O}$ ato de rememorar de artesãs sobre o fazer crochê, perpassa pela observação dos movimentos das laçadas das mãos femininas de sua árvore genealógica - avó, mãe, irmã mais velha e tias. Olhar curioso em primeiro momento, para copiar depois os gestos das mãos e do corpo e enfim, experienciar a memória afetiva, astúcia e imaginação no ato de criação.

\section{Considerações finais}

Pensando nas tramas da vida na atualidade pode-se proporcionar um panorama diversificado de experiências femininas e estimulo à prática do crochê como recurso em qualidade de vida e novas possibilidades perante a realidade que se descortina no novo mundo.

Verifica-se que o crochê pode incentivar as pessoas a descobrirem, por meio da arte de tecer fios, o universo desta atividade da cultura popular, que relata histórias de vidas do universo feminino. 
O desenvolvimento cultural de uma sociedade advém da maneira que ela constrói seus bens e valores. Os artefatos, por surgiram dos saberes, costumes e artifícios transmitidos através das gerações, são elementos da formação de identidade de seus filhos, compondo-se como "cultura material". Termo este que surgiu no século XIX e expandiu-se para uma "maneira de melhor entender os artefatos que produzimos e consumimos, bem como a maneira em que estes se encaixam em sistemas simbólicos e ideológicos mais amplos" (FACHONE, 2012, p. 37).

A arte do crochê é cercada de hipóteses desde sua origem, mas não há como negar que é um saber tradicional que transita na memória de diferentes culturas. Como atividade imaginada e criada no universo feminino afetivo, pode-se dizer que, além de ser um ofício promovedor de renda familiar, é principalmente um instrumento de histórias, como observado nos grupos de artesãs desta pesquisa. Deste modo, aprender da arte do crochê envolve múltiplas variáveis e o fator econômico não é um empecilho (há sempre algum material que pode ser utilizado com suporte).

Crochê como arte pertencente à Cultura Popular, cada vez mais, ocupa áreas como o design, arte e moda, descortinando os valores do artesanato na sociedade, assim observa-se uma valorização dos elementos e habilidades que compõem a essência cultural de uma sociedade. Alguns designers e artistas usam o crochê até como manifestação artística urbana e fazem instalações em cidades cosmopolitas para lembrar as pessoas que elas têm, literalmente, que respirar e viver. As transformações do espaço podem marcar profundamente a vida do morador de uma cidade. Algumas afetam diretamente o cotidiano das pessoas e da cidade como um todo.

Construir constantemente, na vivência humana, práticas que fortalecem a tradição tem caráter de dinamismo e de ação transformadora de realidades no universo feminino; saberes e fazeres impactantes e afetivos que abrem caminho para reflexões acerca da construção da felicidade diante dos acontecimentos atuais mundiais.

\section{Design and crochet in the female universe}

\section{Abstract:}

Crochet is a dive of introspection and realization of the know-how reported by empowered women who, when holding needles and threads in their hands, distance themselves from everyday issues. This statement comes from a survey of artisans and artists for their knowledge and skills in handmade production with crochet in traditional communities and urban environments. We sought to understand why the statement that crochet, in addition to work, serves as therapeutic activities for some women. The research also sought to observe the presence of crochet in the contemporary world, especially in the current moment of social isolation in the Brazilian territory. Using the qualitative method, this work is based on artisanal relationships with design and its social contributions. In results, a diversified panorama of female experiences is presented and I encourage the practice of crochet as a resource in quality of life and new possibilities in the face of the reality that unfolds in the new world.

\section{Keywords:}

Design; crochet; feminine gender; quality of life; happiness

\section{Referências bibliográficas}

ALMEIDA, NAOMAR. Modelos de determinação social das doenças crônicas não-transmissíveis, In: Ciência \& Saúde Coletiva, v.9 n.4 (865-884), RJ, ABRASCO, 2004.

ANDRADE, Louise dos Reis Gusmão. Um lugar de memória: a subjetividade do bordado na instalação artística. Trabalho de conclusão de curso (Licenciatura em Artes Visuais) - Universidade Federal do Rio Grande do Norte, Natal, 2017. 
BARBOSA, Vera Lúcia Ermida. Mulher e artesanato: as artesãs do povoado do Bichinho/Prados-MG. 2014. Dissertação (Mestrado em Psicossociologia de Comunidades e Ecologia Social) - Universidade Federal do Rio de Janeiro, Rio de Janeiro, 2014.

BOGO, A. Identidade e luta de classes. $1^{\circ}$ ed. São Paulo: Expressão Popular, 2008. p. 30-31.

BOSI, Alfredo. Reflexões sobre arte. São Paulo: Ática, 1986.

CAROLINA Ponte. In: Enciclopédia Itaú Cultural de Arte e Cultura Brasileiras. São Paulo: Itaú Cultural, 2020. Disponível em: <http://enciclopedia.itaucultural.org.br/pessoa375363/carolina-ponte>. Acesso em: 29 de Jul. 2020. Verbete da Enciclopédia. ISBN: 978-85-7979-060-7

CERQUEIRA, F. V. Novas diretrizes para a proteção do patrimônio: a diversidade cultural e o imaterial. Métis: história \& cultura, Caxias do Sul, v. 12, p.40-63, dez. 2012.

CURCULO.COM.BR. Dia Mundial do Crochê 2019: confira como foi essa semana especial! Disponível em: https://www.circulo.com.br/dia-mundial-do-croche-2019/. Acesso em: 26 jul. 2020.

DEPAULO, J. R., HORTIZ, L. A. Understanding Depression; Jonh Wiley \& Sons. 2000.

DIAS, Marina. Ela tece fios e esperança. Revista Encontro. Postado em: 21 jul. 2014. Disponível em: https://www.revistaencontro.com.br/canal/revista/2014/07/ela-tece-fios-e-esperanca.html. Acesso em: 26 jul. 2020.

DONDIS, A. Donis. Sintaxe da Linguagem Visual. Tradução: Jefferson Luiz Camargo, Martins Fontes, 2000.

D'ORNELAS, Stephanie. Crochê vira arte urbana e dá cor às cidades em várias iniciativas pelo mundo. Gazeta do Povo. Postado em: 15 jan. 2018. Disponível em:

https://www.gazetadopovo.com.br/haus/urbanismo/croche-vira-arte-urbana-cor-cidade-mundo/.

Acesso em: 13 maio 2020.

DUMAZEDIER, Joffre. Lazer e cultura popular. MACHADO, Maia de Lourdes Santos (trad.). São Paulo: Perspectiva, 1973.

ENGELS, Friedrich. A Origem da Família, da Propriedade Privada e do Estado. RJ, Civilização Brasileira, 1985.

FACHONE, Savana Leão. Design e artesanato: o sentido do fazer manual na contemporaneidade. 2012. Dissertação (Mestrado em Design) - Universidade Anhembi Morumbi, São Paulo, 2012.

FOLHA DE SÃO PAULO. Artista usa 'grafite de crochê' para levar mensagens às ruas de SP. Postado em: 30 jun. 2016. Disponível em:

https://www1.folha.uol.com.br/saopaulo/2016/06/1787308-artista-usa-grafite-de-croche-paraespalhar-mensagens-nas-ruas-de-sp.shtml. Acesso em: 13 de mai. 2020.

FONSECA, Erika Luiza da. O bordado como representação simbólica no atendimento arteterapêutico. In: Arterevista, n. 5, jan./jun. 2015, p. 43-5. Disponível em:

http://www.fpa.art.br/fparevista/ojs/index.php/00001/article/view/59/100. Acesso em: 13 de mai. 2020.

GEHL, J. Cidades para Pessoas. São Paulo: Perspectiva, 2013.

GUEDES, Maria Heliana Mota; GUEDES, Helisamara Mota; ALMEIDA, Martha Elisa Ferreira de. Efeito da prática de trabalhos manuais sobre a autoimagem de idosos. Rev. Bras. Geriatr. Gerontol., Rio de Janeiro, RJ, 2011. Disponível em: https://www.scielo.br/pdf/rbgg/v14n4/a12v14n4.pdf. Acesso em: 12 jun. 2020.

KELLY, E. Design e artesanato: um diferencial cultural na indústria do consumo. ACTAS DE DISEÑO, v. 1, p. 01-15, 2007.

LEMES, Bianca Xavier; PEREIRA, Andréa Franco. Tecer e empoderar: as entrelinhas do saber-fazer do crochê de um grupo de mulheres artesãs. In: Multitemas, Campo Grande, v. 25, n. 169-190, jan./abr. 2020.

MAIA, Ivan Ferrer. De ponto em ponto. Revista da Cultura. Livraria Cultura-Ed. Número 80. março 2014 , p. 61,62 . 
MARKS, Ruthie. History of crochet. 1997. Disponível em:

<http://www.crochet.org/?page=CrochetHistory>. Acesso em: 19 de jun. 2020.

MARTINS, Saul. Contribuição ao estudo científico do artesanato. Belo Horizonte: Imprensa Oficial do Estado de Minas Gerais, 1973.

MDIC - MINISTÉRIO DO DESENVOLVIMENTO, INDÚSTRIA E COMÉRCIO EXTERIOR SECRETARIA DE COMÉRCIO EXTERIOR. Termo de Referencia do Artesanato - Art. 40 da Portaria MDIC N029/2010. Disponível em: http://www.mdic.gov.br/arquivos/dwnl_1291902104.pdf. Acesso em 27 jul. 2020.

MELO, Marcela Araujo. Intervenções urbanas e Design: práticas para a reconstrução do tecido social. Dissertação (Mestrado em Design), Belo Horizonte: UEMG, 2016.

MELO, Marcela Araujo; SILVA, Sérgio Antonio. Textos urbanos: dispositivos de emoção para transformação social. Revista Estudos em Design. Rio de Janeiro: vol. 24, nº. 3, 2016.

MOURÃO, Nadja Maria; OLIVEIRA, Ana Célia Carneiro. Cultura afetiva: a construção do ser brincante no contexto urbano externo. RELACult - Revista Latino-Americana de Estudos em Cultura e Sociedade. Vol.06, artigo n01789, ed. especial, mar/2020. ISSN 2525-7870. Disponível em: http://periodicos.claec.org/index.php/relacult/article/view/1789. Acesso em: 26 jul. 2020.

PALUDAN, Lis. Crochet: History \&Tecnique. Loveland, CO: Interweave Press, 1995.

PEDRO, Fernanda Lopes; ALVES, Carla Juliana Galvão. Alinhavando Memórias a uma Produção Visual. Anais do VII Encontro Nacional de Estudos da Imagem/IV Encontro Internacional de Estudos da Imagem. Londrina: Universidade Estadual de Londrina, 2019.

RICHTER, Ivone Mendes. Interculturalidade e estética do cotidiano no ensino de artes visuais. Campinas, SP: Mercado de Letras, 2003.

SANTOS, S. A. Os saberes e fazeres das parteiras na comunidade Kalunga, Ribeirão dos Bois, Teresina - GO (Monografia) Universidade de Brasília/ Faculdade UnB, Planaltina, 2015.

SANTOS, Vanessa Sardinha dos. "Dopamina "; Brasil Escola. Disponível em: https://brasilescola.uol.com.br/biologia/dopamina.htm. Acesso em 09 de agosto de 2020.

SENNETT, Richard. 0 artífice. 5. ed. Rio de Janeiro: Record, 2015.

VAZ, Rita Isabel; PANEK, Bernadette Maria. Tecendo memórias, atraindo olhares: a apropriação de padrões ornamentais e decorativos na expressão artística. In; Revista Inter. Interdisc.

Art\&Sensorium, Curitiba, v.4, n.2, p. 322 - 337 jul./dez. 2017.

VERAS, E. K. R. S. Crochê e Richelieu: Traços Culturais no Design Brasileir Diseño en Palermo. Encuentro Latinoamericano de Diseño, Palermo, 2007.

WILSON, Jacque. This is your brain on crafting. Disponível em:

<http://edition.cnn.com/2014/03/25/health/brain-crafting-benefits/index.html>. Acesso em: 13 mai. 2020. 